\title{
SUSTAINABILITY AND SPECTRUM MANAGEMENT IN THE 6G ERA
}

\author{
Marja Matinmikko-Blue
}

Centre for Wireless Communications (CWC), University of Oulu, Finland

\begin{abstract}
The goal of sustainability and the required sustainable development to reach this goal call for a significant renewal of operations to solve fundamental challenges facing societies. The role of ICT and wireless communications is critical in realizing the twin transition of green and digital. The wireless and mobile communications community has taken sustainability as the key goal driving the whole $R \& D$ of the next generation of mobile communication networks (6G) aiming at deployment in 2030s. Understanding the triple bottom line of economic, social and environmental sustainability together with the concrete United Nations Sustainable Development Goals (UN SDGs) with specific targets and indicators are fundamental for $6 G R \& D$ but their linkages are not yet clear. This paper investigates sustainability and sustainable development in the context of 6G. A special focus is on the management of the fundamental natural resource for wireless communications, namely the radio spectrum whose management keeps getting ever more complex. The paper highlights the role of new sharing-based spectrum governance models, to rapidly respond to the needs of the changing world towards a sustainable future.
\end{abstract}

Keywords $-5 \mathrm{G}, 6 \mathrm{G}$, mobile communications, regulation, spectrum management, sustainability, sustainable development, UN SDG

\section{INTRODUCTION}

Sustainability has become the major long-term goal of operations of all sectors of society and the ICT sector is no exception. In general, sustainability refers to the "principle of ensuring that our actions today do not limit the range of economic, social, and environmental options open to future generations" [1]. Sustainable development, on the other hand, refers to the "development that meets the needs of the present without compromising the ability of future generations to meet their own needs", as defined in the World Commission on Environment and Development's 1987 Brundtland report 'Our Common Future'. Sustainability can significantly benefit from the use of wireless and mobile communications technologies.
Today's wireless and mobile communication R\&D activities in academia, industry and regulation are increasingly addressing the use of $5 \mathrm{G}$ networks and other technologies in different vertical sectors of society, such as industry, healthcare, and energy, serving their specialized needs in specific geographical locations. Its roots are in the emergence of new local $5 \mathrm{G}$ operator models [2-3] leading to new business models and ecosystems [4], calling for a reconsideration of the existing regulatory framework [5]. In recent years, several regulators have taken $5 \mathrm{G}$ spectrum actions that make it possible for different stakeholders to operate their own local networks to serve a variety of user groups through local spectrum licensing [5-6]. This paradigm shift from only Mobile Network Operator (MNO) cellular networks towards opening the market for new local networks, established by a variety of stakeholders, brings the networks closer to the different vertical sectors of society, which face urgent need to renew their operations to meet sustainability requirements set by governments.

Recent $6 \mathrm{G}$ research has been built on the consensus of addressing sustainability and required sustainable development actions from the beginning of development [7]. This early agreement on sustainability being the key driver for 6G development from 2019 [7] was further detailed in [8], by linking $6 \mathrm{G}$ and the United Nations Sustainable Development Goals (UN SDGs) through indicators. This connection opens a new consideration on how wireless networks could assist in the collection of data necessary for the achievement of sustainable development targets [9]. Other parallel $6 \mathrm{G}$ research efforts have similarly taken sustainability as the fundamental driver, e.g., see [10].

While sustainability through the triple bottom line of economic, social, and environmental sustainability from [1] and the needed sustainable development through the UN SDG framework [9] are of utmost importance for 6G R\&D, their complex relationship has not been thoroughly addressed. The dual role of ICT, or more specifically mobile communications, as a provider of services to help other sectors reach sustainability goals and the sector's own sustainability impact are two different facets that both need careful analysis and strategic actions, e.g., see [11]. While helping others via mobile communications is critical, the wireless sector, however, has to incorporate of sustainability 
into all operations including the use of resources, such as the radio spectrum.

Regulators have noted that radio spectrum is a fundamental enabler for sustainable development, enabling key associated technologies, including universal broadband coverage, and digital transformation CO2-footprint reduction [12]. Radio spectrum is a fundamental natural resource for wireless communications, and its management continues to be contentious [13]. Sustainability and spectrum management, including sustainable development actions, is an unexplored topic. Spectrum access rules are fundamental for deploying new wireless systems, driving or limiting development and ultimately defining market structures. Spectrum decisions also define how new innovative approaches to combat the sustainability challenges using wireless technologies can be introduced. 5G spectrum decisions have adopted local licenses in some countries, which has led to new business opportunities but also fragmentation. This places nations in different starting points for sustainable development.

This paper brings sustainability into the $R \& D$ of future wireless networks. It analyzes what needs to be considered within traditional spectrum management policies for future wireless networks (i.e., 6G), especially through sustainable development as defined in the UN SDG framework.

The rest of this paper is organized as follows. Section 2 reviews ongoing joint $6 \mathrm{G}$ vision building work. Section 3 investigates the state of the art on the role of sustainability and sustainable development in $5 \mathrm{G}$ and $6 \mathrm{G}$. Section 4 focuses on the state of the art on spectrum management in $5 \mathrm{G}$ and 6G. Finally, Section 5 gives author recommendations on the sustainability and spectrum management perspectives for the $6 \mathrm{G}$ era, bringing these two perspectives together, followed by conclusions.

\section{BUILDING A JOINT 6G VISION}

First, we look at the state of the art of joint $6 \mathrm{G}$ vision building.

\subsection{Building blocks of $6 \mathrm{G}$ vision}

Joint 6G vision building got kick-started in March 2019 with the world's first large-scale global $6 \mathrm{G}$ event, the $6 \mathrm{G}$ Wireless Summit organized by the Finnish 6G Flagship program [14]. The event culminated in the publishing of the world's first 6G White Paper in September 2019 [7] as a collaborative effort of 70 invited experts globally. It summarized the $6 \mathrm{G}$ vision as "ubiquitous wireless intelligence", and a major agreement was that sustainability is the key driver for $6 \mathrm{G}$.

The joint $6 \mathrm{G}$ vision effort was followed by the establishment of 12 open thematic expert groups, leading to 12 white papers in 2020-2021 by the 6G Flagship. These papers addressed many aspects of 6G, as well as UN SDGs, including sustainability and also radio frequency (RF) and spectrum [15].
The European Flagship project Hexa-X has presented its $6 \mathrm{G}$ vision in [10] as a joint effort of 25 organizations. This vision is about the interactions of a human world of our senses, bodies, intelligence, and values; a digital world of information, communication, and computing; and a physical world of objects and organisms. The six main research challenges considered in Hexa-X include connecting intelligence, the network of networks, sustainability, global service coverage, extreme experience, and trustworthiness, which also stresses the importance of sustainable development.

The 6G vision by authors in [16] envisages holographic communications and delay-sensitive AI applications and discusses sub-terahertz and visible light communications and massive use of multi-radio access technologies and multilink techniques as enabling technologies. Authors in [17] present a large-dimensional and autonomous network architecture that combines space-air-ground-underwater networks. 6G vision in [18] stresses the role of socio-technical design of 6G and introduces additional senses and emotions as $6 \mathrm{G}$ applications, proposing ultra-long battery life as a key requirement. $6 \mathrm{G}$ vision in [19] expects new themes to emerge, such as new man-machine interfaces, ubiquitous universal computing, multi-sensor data fusion, and precision sensing and actuation to control the physical world.

The International Telecommunication Union (radiocommunication sector ITU-R) has started the global process for defining the mobile communications systems that will be used in 2030s, 6G, in the form of International Mobile Telecommunication (IMT) for 2030 and beyond. ITU-R has launched technology trends and vision work for IMT for 2030 and beyond, aiming at completion in June 2022 and June 2023, respectively. This process brings together different stakeholder perspectives into a true joint $6 \mathrm{G}$ vision.

\subsection{Emerging local networks and changing business ecosystem}

While wireless communication research is largely about new technology development, there is an ever-increasing need to address related business and regulation considerations, since the deployment and use of new technology depends on them. The emergence of local $5 \mathrm{G}$ networks through a new local operator deployment model allowing different stakeholders to deploy $5 \mathrm{G}$ networks within specific premises without direct MNO involvement is already changing the mobile business ecosystem [2-3]. These local networks can serve a variety of user groups including closed groups resulting in private or non-public networks, or open user groups, such as MNOs' customers resulting in neutral host, or a mix of these. These deployment models can fall under different regulatory regimes, which influences their deployment and adoption [4] Their emergence is a highly national matter depending on spectrum availability. In the lead up to $6 \mathrm{G}$, local networks will become increasingly important, resulting in the potential emergence of a large number of local networks deployed by different stakeholders, making the resulting business ecosystem more complex [7, 20-21]. 
The changing business ecosystems in $5 \mathrm{G}$ will further change in $6 \mathrm{G}$ [20-21], where new roles emerge to serve the diverging needs with different resource combinations. While MNO market dominance is expected to continue in $5 \mathrm{G}$, future $6 \mathrm{G}$ connectivity solutions will be driven by new market players [20-21]. There will be a range of needs from human and machine users in different verticals, both from public and private sectors, in their attempts to renew their operations towards sustainability goals. The resources and assets needed will be provided by a range of stakeholders for physical infrastructure, equipment, and data, under their respective regulatory frameworks. Needs and resources are brought together through matching resources from different stakeholders via new stakeholder roles, including different kinds of operators, resource brokers, and various service and application providers [20-21].

This development depends on spectrum availability in the given area, at the time of interest, for the deployment of any wireless network. Local mobile communication networks can be deployed by the traditional MNOs using their existing spectrum bands. For others, future operations are fully dependent on regulators' spectrum decisions, which in $5 \mathrm{G}$ spectrum awards has become a major differentiating factor among countries leading to different competitive advantages.

\section{STATE OF THE ART OF THE ROLE OF SUSTAINABILITY AND SUSTAINABLE DEVELOPMENT IN 5G AND 6G}

This section investigates the big goal of sustainability and the needed sustainable development to reach this goal in the context of future $6 \mathrm{G}$ networks.

\subsection{Sustainability}

Sustainability's importance has increased recently to become the single most influential driver of operations across sectors. Elkington noted in [1] that driving companies' sustainability requires dramatic changes in their performance against the triple bottom line of economic, social and environmental areas. In particular, what is between these areas can be of specific importance. Stringent requirements are starting to emerge to different verticals and the mobile communications sector can help other vertical sectors in their renewal of operations towards reaching sustainability.

Authors in [22] outlined economic, social, and environmental sustainability aspects in the context of $6 \mathrm{G}$ and outlined research challenges for $6 \mathrm{G}$. Economic sustainability should have no negative consequences on social or environmental sustainability, social sustainability should not compromise economic or environmental sustainability, and environmental sustainability should not sacrifice social or economic sustainability.

\subsection{Sustainable development through the UN SDG framework}

The actual development towards sustainability, i.e., sustainable development, is thoroughly characterized in the UN SDG framework that presents 17 goals with 169 targets whose achievement is monitored through 231 individual indicators [9]. In the UN SDG framework, 7 indicators are considered to be ICT-related and connected to 4 of the 17 SDGs. However, there is a much closer connection between ICT, especially mobile communications, and the UN SDGs, as outlined in [23-24]. The role of mobile communications is fundamental for many UN SDGs through the three layers: 1) deployment of infrastructure and networks forming the needed foundation for digital economy; 2) access and connectivity through providing people the opportunity to use mobile communications; and 3) enabling services and relevant content that provides life-enhancing services for people [23]. A connection between the UN SDG framework and $6 \mathrm{G}$ was established in [7] and further detailed in [8]. The WPC paper further details the linkage between all 17 UN SDGs and mobile communications.

Prior research on ICT and UN SDGs in [25] has used the classification of economic, social and environmental UN SDGs by introducing a division for the 17 SDGs into these three categories. From the SDG, Wu et al. (2018) divide \#1, $\# 2$, \#3, \#8 and \#9 to economic SDGs, \#4, \#5, \#10, \#11, \#16 and \#17 to social SDGs, and \#6, \#7,\#12,\#13, \#14, and \#15 to environmental SDGs. However, this split is oversimplistic as all SDGs have aspects relevant of the triple bottom line restricting the usefulness of such splitting. The goals presented in the UN SDG framework are highly interrelated and the achievement of one target can negatively impact another target which is why looking at the UN SDGs independently is not enough.

Wireless research has investigated the environmental bottom line of sustainability through energy and other resource efficiencies for a long time, especially regarding green communications. The 20 years of research on green radios summarized in [26] consider spectrum efficiency and energy efficiency in wireless networks and end-user devices as essential for sustainability through a multitude of methods. Wireless communications have fundamental green trade-offs from the theoretical relations between the pairs of spectrum efficiency, energy efficiency, deployment efficiency, delay, power, and bandwidth, which are reviewed for $5 \mathrm{G}$ networks in [27].

The role of MNOs is crucial in the sustainability of mobile communications and an MNO perspective on $5 \mathrm{G}$ is presented in [28], where energy consumption of the radio access network is evaluated in different load conditions. Another MNO view is given in [29] on the environmental and economic feasibility of MNOs becoming carbon neutral, combining two of the bottom lines. Authors in [30] present methods for evaluating and reducing the network's energy consumption. This need for resource efficiency, especially energy efficiency, is important towards the future wireless 
systems and calls for new methods to evaluate resource efficiency and consumption.

There is an urgency to address resource, and particularly energy, efficiency aspects for $6 \mathrm{G}$ systems. The ITU-R process for IMT for 2030 and beyond will eventually define the technical performance requirements for future mobile communication systems and proper metrics and evaluation methods are needed to introduce energy efficiency into the technical performance requirements framework.

\section{STATE OF THE ART ON THE ROLE OF SPECTRUM MANAGEMENT IN 5G AND 6G}

All wireless communications use radio spectrum, whose management has been the source of contentious debate for a century. Spectrum management decisions are about the governance of the natural resource, defining who, where, when, how and for what purpose a specific frequency band is used.

\subsection{Spectrum governance models}

Spectrum management coordinates the use of this scarce resource between the different wireless systems resulting in complicated governance of public goods [31]. Successful spectrum management requires the balancing of conflicting stakeholder claims on the use of the precious resource. Any wireless system, existing or entrant, needs to operate in accordance with the Radio Regulations of the ITU-R.

In general, spectrum management attempts to maximize the value of spectrum, its efficient utilization, and its benefits to society [32]. The choices spectrum regulators make in their allocation and authorization decisions define the market structures. They aim to be effective by allocating spectrum to the right use, and efficient by assigning it to those who value it the most [32]. The time spans in spectrum management are long, often decades, and these decisions are meant to define the markets for long periods. The general goal of maximizing the value of spectrum and its efficient use can be interpreted in many different ways, leading to different outcomes between countries. This decision making has had enormous political and economic significance over several decades, see [33].

Spectrum governance models can be divided into administrative allocation, market-based mechanisms and the unlicensed commons approach [6]. Administrative allocation, also known as hierarchical command and control approach, was traditionally used to give spectrum access rights to those requesting them [34]. The regulator decides who gets the spectrum access rights using its own criteria through e.g., direct awards or beauty contests. Market-based mechanisms are nowadays typically used for commercial wireless communications such as mobile communication networks [33, 35]. They define spectrum property rights which are distributed to stakeholders via market mechanisms, such as auctions, introducing the value of spectrum as a decision-making factor. Often secondary spectrum markets are allowed for trading [36], where the rights can be transferred to other stakeholders. The unlicensed commons approach typically allows spectrum access to several different types of usages and users under regulatory defined rules and conditions. It often involves low-power wireless devices restricting interference locally. The unlicensed commons approach has resulted in new profits and promoted innovation and competition through faster access to spectrum for several stakeholders despite perceived quality concerns.

The different spectrum management models involve varying levels of spectrum sharing, which according to the ITU-R report [37] refers to the situation where two or more radio systems use the same frequency band. Recently, many regulators have promoted spectrum sharing, including [13].

\subsection{The struggle of governing the commons}

The management of natural resources takes places in a number of fields, as summarized in [38]. Thus, the general rules for the governance of natural common pool resources can help in the spectrum management domain in the development of efficient mechanisms for the future wireless systems including 6G. Promising strategies from the management of natural resources through adaptive governance in [38] include involving interested partied in informed discussion of rules (analytical deliberation), allocation of authority to allow for adaptive governance at multiple levels from local to global (nesting) and employing a mixture of institutional types (institutional variety).

Anker proposed a new spectrum governance process where the role of the government shifts from a controller of to a facilitator of decentralized coordination in a multi-actor governance process in [31]. This process implements both spectrum property rights and an unlicensed commons approach to optimize the functioning of the market where the role of government remains as a monitor of the system, to guide or correct the market, if necessary. New spectrum sharing arrangements are promoted, which can benefit from a platform to build trust among stakeholders. Such a process is needed for future wireless systems.

The $5 \mathrm{G}$ spectrum awards decisions show an interesting step towards the $6 \mathrm{G}$ era. European pioneer bands for $5 \mathrm{G}$ include $700 \mathrm{MHz}, 3.5 \mathrm{GHz}$ and $26 \mathrm{GHz}$ and their awards are completed in several countries. Recent analyses of the outcomes have shown high divergence in the approaches taken by regulators in $5 \mathrm{G}$, especially the emergence of local $5 \mathrm{G}$ networks by non-MNO stakeholders is treated very differently [6]. The bands have very distinct propagation characteristics resulting in different suitable deployment models. However, some countries have used exactly the same awarding mechanisms for all bands while others have introduced different methods. This has led to market fragmentation, especially regarding the availability of local spectrum licenses as proposed in [5]. Table 1 summarizes different spectrum management approaches in the context of $5 \mathrm{G}$, with a focus on how local networks are considered. 
Table 1 - Spectrum management approaches in $5 \mathrm{G}$

\begin{tabular}{|l|l|l|}
\hline $\begin{array}{c}\text { Spectrum } \\
\text { management } \\
\text { approach }\end{array}$ & \multicolumn{1}{|c|}{ Role in 5G } & \multicolumn{1}{c|}{$\begin{array}{c}\text { Local network } \\
\text { perspective }\end{array}$} \\
\hline $\begin{array}{l}\text { Administrative } \\
\text { allocation }\end{array}$ & $\begin{array}{l}\text { Less used in 5G } \\
\text { but made a come- } \\
\text { back in local 5G } \\
\text { spectrum awards }\end{array}$ & $\begin{array}{l}\text { First-come first served } \\
\text { nowadays used for } \\
\text { awarding spectrum for } \\
\text { local 5G networks }\end{array}$ \\
\hline $\begin{array}{l}\text { Market-based } \\
\text { mechanism }\end{array}$ & $\begin{array}{l}\text { Dominant method } \\
\text { in 5G through } \\
\text { auctions, } \\
\text { typically MNOs } \\
\text { acquire licenses. }\end{array}$ & $\begin{array}{l}\text { MNOs can deploy local } \\
\text { networks in their } \\
\text { licensed bands. License } \\
\text { holders can also trade } \\
\text { spectrum for local } \\
\text { networks to different } \\
\text { stakeholders. }\end{array}$ \\
\hline $\begin{array}{l}\text { Unlicensed } \\
\text { commons }\end{array}$ & $\begin{array}{l}\text { 5G technologies } \\
\text { developed for } \\
\text { operations under } \\
\text { the unlicensed } \\
\text { commons } \\
\text { approach. }\end{array}$ & $\begin{array}{l}\text { Possible for any } \\
\text { stakeholder to deploy a } \\
\text { network without a } \\
\text { license subject to } \\
\text { operational conditions } \\
\text { in the band. }\end{array}$ \\
\hline
\end{tabular}

\section{RECOMMENDATIONS FOR THE 6G ERA}

The goal of sustainability through sustainable development and the role of spectrum management in this development, are brought together for the future $6 \mathrm{G}$ era by providing recommendations for the future.

\subsection{Sustainability perspective}

Driving 6G towards the big goal of sustainability through sustainable development requires a major rethink of existing practises against the triple bottom line of economic, social and environmental sustainability from [1]. Since most interesting challenges are found between these three bottom lines, special emphasis should be put on new innovations at the intersections. Table 2 outlines implications of the triple bottom line of sustainability on $6 \mathrm{G}$ development.

The role of wireless technologies for emitting less is equally important, as is support for absorbing more in the other sectors of society where impact could be achieved. Both need to be addressed. As envisaged in the joint $6 \mathrm{G}$ vision building, 6G will combine communication services with other services, such as imaging, 'sensoring', and 'locationing' [7], providing a measurement tool to collect various data at hyperlocal granularity [8], which can be used to steer operations towards sustainability targets [9]. The elaboration of this new role as a measurement tool needs further attention.

The need for significant improvement of energy efficiency of the wireless networks themselves is evident for $6 \mathrm{G}$ and the development of new measures, measurement methodologies and techniques for improving energy efficiency of networks from end to end is urgent. Better analysis of the impacts of operating frequency and other elements on energy consumption is needed. New mechanisms need to be developed to reduce the carbon footprint through sharing all potential wireless communication resources. Additionally, the network architecture has a significant impact on total energy consumption. Optimization of the collection, processing, storage and transfer of data between different locations and components becomes a complex task and calls for the development of new metrics and measurement methods to assess the sustainability of such solutions including end-to-end energy consumption through different network configurations.

The telecommunication industry and operators play a key role in the ICT sector's attempts to combat climate change. The telecommunication sector itself needs to go through a major renewal of its own operations to contribute to meeting sustainability targets, in addition to its role as an enabler to renew the operations of other sectors of society. Selfassessment of its own operations and reporting on emissions and actions to achieving environmental targets is an important starting point. The process should not be left only in the hands of the telecommunication industry including operators, which corresponds to self-evaluation. This requires an open approach where the research community can contribute its findings to the process. Detailed data and actions on energy efficiency and energy consumption among other sustainability-related metrics should be made available to the research community to allow researchers to develop new methods to assess and reduce resources efficiently and consumption based on real data, which today is a true bottleneck. Therefore, sharing of methods and data on the impact of the wireless communications sector between the telecommunication industry, operators, and academia as well as sectors that could benefit from wireless technologies needs to be promoted.

Table 2 - Triple bottom line of sustainability and 6G

\begin{tabular}{|l|l|l|}
\hline $\begin{array}{c}\text { Sustainability } \\
\text { element [1] }\end{array}$ & \multicolumn{1}{|c|}{ Description [1] } & \multicolumn{1}{|c|}{$\begin{array}{c}\text { Implication on 6G } \\
\text { development }\end{array}$} \\
\hline $\begin{array}{l}\text { Economic } \\
\text { sustainability }\end{array}$ & $\begin{array}{l}\text { Ensuring } \\
\text { profitability of } \\
\text { business operations } \\
\text { (economic capital) }\end{array}$ & $\begin{array}{l}\text { New business } \\
\text { opportunity to help } \\
\text { different sectors to } \\
\text { reach sustainability. } \\
\text { Deployment of } \\
\text { developed technology } \\
\text { is affordable. }\end{array}$ \\
\hline $\begin{array}{l}\text { Social } \\
\text { sustainability }\end{array}$ & $\begin{array}{l}\text { Contributing human } \\
\text { capital (e.g., public } \\
\text { health, skills and } \\
\text { education) and } \\
\text { wider measures of a } \\
\text { society's health and } \\
\text { wealth creation } \\
\text { potential (social } \\
\text { capital) }\end{array}$ & $\begin{array}{l}\text { Increasing role of } \\
\text { users (humans and } \\
\text { vertical sectors) in } \\
\text { defining 6G } \\
\text { requirements. } \\
\text { Decrease digital } \\
\text { divide to include all to } \\
\text { society and leave no- } \\
\text { one behind. }\end{array}$ \\
\hline $\begin{array}{l}\text { Environmental } \\
\text { sustainability }\end{array}$ & $\begin{array}{l}\text { Forms of critical } \\
\text { and renewable } \\
\text { natural capital that } \\
\text { are impacted by } \\
\text { operations (natural } \\
\text { capital) }\end{array}$ & $\begin{array}{l}\text { New indicators } \\
\text { needed for 6G to } \\
\text { assess its } \\
\text { environmental impact } \\
\text { e.g., energy efficiency } \\
\text { and consumption. }\end{array}$ \\
\hline
\end{tabular}




\subsection{Spectrum management perspective}

Although it is still early to talk about specific spectrum bands for $6 \mathrm{G}$, a wider range of bands are already under consideration in research than in $5 \mathrm{G}$ that in turn expanded the spectrum range from $4 \mathrm{G}$ to millimeter wave bands, e.g., see [39-40]. This is potentially leading to increasing complexity of spectrum management approaches suitable for the wide mix of bands and potentially ever-increasing fragmentation between countries. Spectrum authorizations and related spectrum management approaches such as administrative allocation, market-based mechanisms, and the unlicensed commons, play a key role in defining future wireless markets. Decisions made today significantly influence $6 \mathrm{G}$ as these systems can be deployed on existing bands for mobile communications just like prior generations were.

It is important to reconsider the role of spectrum sharing in accommodating stakeholders' changing and conflicting spectrum needs to reach long-term compromises. Spectrum access models based on sharing can be particularly effective for serving local and temporal spectrum needs by various stakeholders who currently do not have dedicated spectrum access rights. Promotion of spectrum sharing is needed for timely access to spectrum for new innovations and to reach long-term compromises between conflicting needs. An example of this is local spectrum licensing where the current rules are typically based on larger exclusion distances reducing the efficiency of spectrum use. As a consequence, spectrum governance rules must evolve when moving towards 6G. Table 3 summarizes the implications to spectrum management in $6 \mathrm{G}$ using the generic approach of [38] for governance of natural resources.

Table 3 - Governance of the commons and spectrum management for $6 \mathrm{G}$

\begin{tabular}{|l|l|l|}
\hline $\begin{array}{c}\text { Strategies for } \\
\text { adaptive } \\
\text { governance of } \\
\text { the commons } \\
\text { [38] }\end{array}$ & \multicolumn{1}{|c|}{$\begin{array}{c}\text { Description } \\
\text { [38] }\end{array}$} & \multicolumn{1}{c|}{$\begin{array}{c}\text { Implication to } \\
\text { spectrum } \\
\text { management in 6G }\end{array}$} \\
\hline $\begin{array}{l}\text { Analytical } \\
\text { deliberation }\end{array}$ & $\begin{array}{l}\text { Involve interested } \\
\text { parties in } \\
\text { informed } \\
\text { discussion of } \\
\text { rules. }\end{array}$ & $\begin{array}{l}\text { Involve old and new } \\
\text { stakeholders including } \\
\text { those without a } \\
\text { current dominant } \\
\text { position. }\end{array}$ \\
\hline Nesting & $\begin{array}{l}\text { Allocate authority } \\
\text { to allow for } \\
\text { adaptive } \\
\text { governance at } \\
\text { multiple levels } \\
\text { from local to } \\
\text { global. }\end{array}$ & $\begin{array}{l}\text { Introduce new } \\
\text { sharing-based } \\
\text { spectrum management } \\
\text { models. Promote } \\
\text { sharing of best } \\
\text { practices to avoid } \\
\text { fragmentation. }\end{array}$ \\
\hline $\begin{array}{l}\text { Institutional } \\
\text { variety }\end{array}$ & $\begin{array}{l}\text { Employ a mixture } \\
\text { of institutional } \\
\text { types. }\end{array}$ & $\begin{array}{l}\text { Adopt a mix of } \\
\text { spectrum management } \\
\text { models resulting in } \\
\text { competition, taking } \\
\text { into account different } \\
\text { spectrum bands' } \\
\text { characteristics for } \\
\text { deployment (one size } \\
\text { does not fit all). }\end{array}$ \\
\hline & & \\
& &
\end{tabular}

\subsection{Bringing sustainability and spectrum management perspectives together}

Finally, we bring together the triple bottom line of sustainability from [1] and the spectrum management for future $6 \mathrm{G}$ systems. Spectrum authorizations ultimately define who can operate wireless systems and how, which eventually creates the actual carbon footprint and other sustainability impact. Spectrum authorizations are a powerful tool to both incentivize and force spectrum users to act towards sustainability goals, including climate action, if desired by the national regulators. Yet, this is under-explored and new studies are urgently needed on the connection between spectrum management and the major sustainability challenges presented in the UN SDG framework [9].

Spectrum authorizations are also fundamental in allowing new market entry for innovative wireless solutions combating sustainability challenges, which is not considered in the current spectrum regulatory framework. There are no proper mechanisms in the current spectrum regulatory framework to allow fast access to spectrum for new innovative wireless solutions and services that aim at solving a major sustainability challenge, such as climate change. Their adoption is restricted by the license-exempt bands, subject to strict operational conditions, which significantly restrict e.g., outdoor operations. The process of gaining access to spectrum is lengthy and complex, while spectrum access needs for new innovative solutions combating sustainability challenges can arise at a rapid speed. The meeting of the emerging needs of new innovations to combat sustainability challenges would benefit from faster access to spectrum through spectrum sharing. While spectrum authorizations are a national matter, the approaches developed and trialed in one country, can through sharing of best practices help the ICT sector at large to develop, trial and deploy innovative wireless solutions to solve sustainability challenges globally. Therefore, sharing-based spectrum access, such as local licensing, should be promoted as a mechanism to provide rapid access to spectrum to solve major sustainability challenges.

This leads to the big topic of sustainability in the context of spectrum management, i.e., the principle of ensuring that our actions today do not limit the range of economic, social, and environmental options open to future generations. How do the 20-year exclusive licenses without obligations to share fit in the new sustainability framework? If current holders of spectrum access rights do not use parts of the spectrum in given areas, they should be made available for others to help in solving major sustainability challenges. Spectrum sharing should be promoted to allow underserved areas to be connected by suitable stakeholders, by making spectrum available where and when it is not used by the existing holders of spectrum usage rights. While this is a national matter, it is of utmost importance that best practices are developed and shared in the spectrum management domain towards sustainability. 


\section{CONCLUSIONS}

This paper has highlighted the importance of the bigger goal of sustainability and the required sustainable development to reach this goal, in the context of wireless communications. Sustainability is now seen as the key driver for the research and development of $6 \mathrm{G}$ systems that are targeting deployment in 2030s, which is also the year that the UN SDGs should be achieved. The triple bottom line of economic, social and environmental sustainability together with the concrete sustainable development targets from the UN SDG framework need to be properly integrated into $6 \mathrm{G}$ design right from the beginning, which this paper has attempted to do.

Spectrum management governing the use of the fundamental resources for wireless communications will play a central role in both spectrum management and sustainability. A major refinement of traditional policies, including the widespread adoption of spectrum sharing will be needed, to allow all sectors to measurably transform their operations. At the same time, sustainability must become visible in the design criteria of $6 \mathrm{G}$ systems in the form of technical performance requirements. Resource efficiency must finally be taken seriously. Future work is needed to develop these measures and methodologies for their monitoring in $6 \mathrm{G}$ networks that can quantify sustainability in the context of wireless systems towards a sustainable future. Finally, new indicators are needed for $6 \mathrm{G}$ that go beyond traditional minimum technical performance requirements and truly characterize societal aspects. To this end, more work on establishing a thorough connection to UN SDGs needs to be established.

\section{ACKNOWLEDGEMENTS}

Funding from Academy of Finland through 6G Flagship (grant 318927) is acknowledged.

\section{REFERENCES}

[1] J. Elkington, "Cannibals with forks: The triple bottom line of 21 st-century business," Capstone Publishing Ltd. 1997.

[2] M. Matinmikko, M. Latva-aho, P. Ahokangas, S. Yrjölä, and T. Koivumäki, "Micro operators to boost local service delivery in 5G," Wireless Personal Communications, vol. 95, no. 1, pp. 69-82, 2017.

[3] J. Zander, "Beyond the Ultra-Dense Barrier: Paradigm Shifts on the Road Beyond 1000x Wireless Capacity," IEEE Wireless Communications, vol. 24, no. 3, pp. 96-102, 2017.

[4] P. Ahokangas, M. Matinmikko-Blue, S. Yrjölä, and H. Hämmäinen, "Platform configurations for local and private $5 \mathrm{G}$ networks in complex industrial multi-stakeholder ecosystems," Telecommunications Policy, vol. 45, no. 5, 2021.
[5] M. Matinmikko, M. Latva-aho, P. Ahokangas, and V. Seppänen, "On regulations for 5G: Micro licensing for locally operated networks," Telecommunications Policy, vol. 42, no. 8, pp. 622 635,2018 .

[6] M. Matinmikko-Blue, S. Yrjölä, V. Seppänen, P Ahokangas, H. Hämmäinen, and M. Latva-Aho, "Analysis of Spectrum Valuation Elements for Local 5G Networks: Case Study of 3.5-GHz Band," IEEE Transactions on Cognitive Communications and Networking, vol. 5, no. 3, pp. 741-753, Sept. 2019.

[7] M. Latva-aho \& K. Leppänen, (eds.), "Key drivers and research challenges for $6 \mathrm{G}$ ubiquitous wireless intelligence," [White paper]. (6G Research Visions, No. 1). University of Oulu, 2019. http://urn.fi/urn:isbn:9789526223544 .

[8] M. Matinmikko-Blue et al. (Eds.) "White Paper on 6G Drivers and the UN SDGs" [White paper]. (6G Research Visions, No. 2). University of Oulu, 2020. http://urn.fi/urn:isbn:9789526226699

[9] United Nations, "Resolution adopted by the General Assembly on Transforming our world: the 2030 Agenda for Sustainable Development (A/RES/70/1)," United Nations, October 2015. https://www.un.org/ga/search/view doc.asp?symbol $=\mathrm{A} / \mathrm{RES} / 70 / 1 \&$ Lang $=\mathrm{E}$.

[10] Hexa-X, "Expanded 6G vision, use cases and key societal values - including aspects of sustainability, security and spectrum," EU project Hexa-X Deliverable D1.2. 2021. https://hexa-X.eu/wpcontent/uploads/2021/05/Hexa-X_D1.2.pdf .

[11] Ministry of Transport and Communications Finland, "Climate and Environmental Strategy for the ICT Sector," Publications of the Ministry of Transport and Communications 2021:6, Finland, 2021. http://urn.fi/URN:ISBN:978-952-243-595-8 .

[12] RSPG; "Draft RSPG Opinion on the role of radio spectrum policy to help combat climate change," Radio Spectrum Policy Group, RSPG21-027 FINAL, June 2021.

[13] RSPG, "RSPG Opinion on Spectrum Sharing Pioneer initiatives and bands," Radio Spectrum Policy Group, RSPG21-022 FINAL, June 2021.

[14] Finnish 6G Flagship research program. www.6gflagship.com (Accessed 12 $2^{\text {th }}$ September 2021).

[15] 6G White Papers published by the 6G Flagship. https://www.oulu.fi/6gflagship/6g-white-papers (Accessed 31st of October 2021). 
[16] E. Calvanese Strinati, et al., "6G: The Next Frontier: From Holographic Messaging to Artificial Intelligence Using Subterahertz and Visible Light Communication," IEEE Vehicular Technology Magazine, vol. 14, no. 3, pp. 42-50, 2019.

[17] Z. Zhang et al., "6G Wireless Networks: Vision, Requirements, Architecture, and Key Technologies," IEEE Vehicular Technology Magazine, vol. 14, no. 3, pp. 28-41, Sept. 2019.

[18] W. Jiang, B. Han, M.A. Habibi, and H.D. Schotten, "The Road Towards 6G: A Comprehensive Survey,". IEEE Open Journal of the Communications Society, vol. 2, pp. 334-366, 2021.

[19] K. David and H. Berndt, "6G Vision and Requirements: Is There Any Need for Beyond 5G?,' IEEE Vehicular Technology Magazine, vol. 13, no. 3, pp. 72-80, Sept. 2018.

[20] S. Yrjölä, P. Ahokangas, and M. Matinmikko-Blue, (eds.), "White Paper on Business of 6G" [White paper]. (6G Research Visions, No. 3). University of Oulu, 2020. http://urn.fi/urn:isbn:9789526226767.

[21] S. Yrjölä, P. Ahokangas, and M. Matinmikko-Blue, "Sustainability as a Challenge and Driver for Novel Ecosystemic 6G Business Scenarios," Sustainability, Vol. 12, No. 21, 2020.

[22] M. Matinmikko-Blue, S. Yrjölä, P. Ahokangas, K. Ojutkangas, and E. Rossi, "6G and the UN SDGs Where is the connection?,"Wireless Personal Communications, 2021.

[23] GSMA. 2020 Mobile Industry Impact Report: Sustainable Development Goals. September 2020.

[24] ITU, "ICTs for a Sustainable World \#ICT4SDG", International Telecommunication Union, 2021. https://www.itu.int/en/sustainable-world/.

[25] J. Wu, S. Guo, H. Huang, W. Liu, and Y. Xiang, Y, "Information and Communications Technologies for Sustainable Development Goals: State-of-the-Art, Needs and Perspectives," IEEE Communications Surveys \& Tutorials, vol. 20, no. 3, pp. 2389-2406, 2018

[26] S. Zhang, S. Xu, G. Y. Li and E. Ayanoglu, "First 20 Years of Green Radios," IEEE Transactions on Green Communications and Networking, vol. 4, no. 1, pp. 1-15, March 2020.
[27] S. Zhang, Q. Wu, S. Xu, and G.Y. Li, "Fundamental Green Tradeoffs: Progresses, Challenges, and Impacts on 5G Networks,". IEEE Communications Surveys \& Tutorials, vol. 19, no. 1, pp. 33-56, Firstquarter 2017.

[28] D. Rapone, D. Sabella, and M. Fodrini, "Energy efficiency solutions for the mobile network evolution towards 5G: An operator perspective," 2015 Sustainable Internet and ICT for Sustainability (SustainIT), Madrid, Spain, 2015.

[29] L.C. Gonçalves, P. Sebastião, N. Souto, and A. Correia, "5G mobile challenges: A feasibility study on achieving carbon neutrality," 2016 23rd International Conference on Telecommunications (ICT), Thessaloniki, Greece, pp. 1-5, 2016.

[30] M. Masoudi et al., "Green Mobile Networks for $5 \mathrm{G}$ and Beyond," IEEE Access, vol. 7, pp. 107270107299, 2019.

[31] P. Anker, "From spectrum management to spectrum governance," Telecommunications Policy, vol. 41, no. 5-6, pp. 486-497, 2017.

[32] F. Beltran, "Accelerating the introduction of spectrum sharing using market-based mechanisms," IEEE Communications Standards Magazine, vol. 1, no. 3, pp. 66-72, 2017.

[33] W. H. Melody, "Radio spectrum allocation: Role of the market," The American Economic Review, vol. 70, no. 2, pp. 393-397, 1980.

[34] H. J. Levin, "Spectrum allocation without market," The American Economic Review, vol. 60, no. 2, pp. 209-218, 1970.

[35] R. Berry, M.L. Honig, and R. Vohra, "Spectrum markets: Motivation, challenges, and implications," IEEE Communications Magazine, vol. 48, no. 11, pp. 146-155, 2010.

[36] T. M. Valletti, "Spectrum trading",

Telecommunications Policy, vol. 25, no. 10-11, pp. 655-670, 2001.

[37] ITU-R, "Cognitive radio systems in the land mobile service," International Telecommunication Union Radiocommunication sector, Report ITU-R M.2330. 2014.

[38] T. Dietz, E. Ostrom, and P.C. Stern, "The Struggle to Govern the Commons," Science, vol. 302, no. 565, pp. 1907-1912, 2003. 
[39] M. Matinmikko-Blue, S. Yrjölä, and P. Ahokangas, "Spectrum Management in the 6G Era: The Role of Regulation and Spectrum Sharing," 2nd 6G Wireless Summit (6G SUMMIT), Levi, Finland, 2020.
[40] A. Pärssinen, et al. (eds.), "White Paper on RF Enabling $6 \mathrm{G}-$ Opportunities and Challenges from Technology to Spectrum," [White paper]. (6G Research Visions, No. 13). University of Oulu, 2021. http://urn.fi/urn:isbn:9789526228419. 